\title{
Research Paper: Relationship Between Selected Performance Tests and Non-contact Sports Injuries in Male Wushu Players
}

\author{
Abbas Ghafouri' ${ }^{1}$ (D) Fariba Mohammadi $^{* *}$ (D), Behnaz Ganji ${ }^{1}$ (D)
}

1. Department of Physical Education and Sport Sciences, Karaj Branch, Islamic Azad University, Karaj, Iran

2. Sport Science Research Institute, Tehran, Iran.

Chtator Ghafouri A, Mohammadi F, Ganji B. Relationship Between Selected Performance Tests and Non-contact Sports Injuries in Male Wushu Players. Physical Treatments. 2020; 10(4):239-249. http://dx.doi.org/10.32598/ptj.10.4.459.1

http://dx.doi.org/10.32598/ptj.10.4.459.1

\section{Article info:}

Received: 11 May 2020

Accepted: 22 Aug 2020

Available Online: 01 Oct 2020
Keywords:

Wushu, Functional Movement Screening (FMS), SEBT, Injury
Purpose: Several tests have been proposed as injury predictor inventories in various sports; however, it is important to recognize which test is more appropriate to predict the injuries of a particular sport. Therefore, the present study aimed to investigate the relationship between selected functional tests and lower limb injuries in elite male wushu athletes.

Methods: In total, 40 wushu player were recruited from the national league (Mean $\pm \mathrm{SD}$ age: 25.1 \pm 4.9 y, weight: $67.3 \pm 7.7 \mathrm{~kg}$, height: $175.3 \pm 4.7 \mathrm{~cm})$. Functional Movement Screening (FMS), Tuck jump, single and double leg squats, Star Excursion Balance Test (SEBT), and Stork balance tests were performed in this research. All of the study variables were measured before the national competition, and after the competition, the rate of the injuries were assessed. The correlation between them was evaluated, subsequently. Descriptive data were used to describe the collected results. Besides, multivariate linear regression analysis was used to explore the relationship between the study variables.

Results: Multivariate linear regression analysis data suggested that LESS, stroke balance test, single-leg squat, and SEBT failed to predict lower extremities injuries; however, Tuck jump, FMS, and double leg squat could predict lower extremities injuries.

Conclusion: Based on the collected results, among the studied tests, trainers and researchers are suggested to employ the Tuck jump, FMS, and double leg squat tests to predict injuries in wushu male players; this test can also be used to prevent injuries in players.

\section{* Corresponding Author:}

Fariba Mohammadi, PhD.

Address: Sport Science Research Institute, Tehran, Iran.

Phone: +98 (939) 9650747

E-mail: mohammadi.ssrc@gmail.com 


\section{Highlights}

- The performance tests such as Tuck jump, Functional Movement Screening (FMS), and double leg squat tests to predict injuries in wushu male players.

- These performance tests can prevent injuries in players.

\section{Plain Language Summary}

Wushu is among the most popular martial arts disciplines, originating in China. Most of the other martial arts are derived from this discipline. Wushu is a martial art that includes a combination of explosive, strength, and speed movements with combat techniques. The prevalence of wushu injuries at the 2009 Asian Championships was higher among women than men. Additionally, the highest prevalence of injury has been recorded in Mutai and Taekwondo. The prevalence of injuries in this discipline, according to studies, is 22807 incidents per 1000 athletes. Wushu competitions are held in the two styles of Sanda and Taolu. The Sanda section is performed as a fighting style, and the Taolu is conducted as a routine practice. Sanda style is more susceptible to injury due to its fighting mode. Performing hard and complicated movements, consistency in performing movements, and stability in performing techniques are the main factors in performing Taolu form in wushu competitions. The instability and vibration of the limbs cause points to be deducted from the athletes. In performing these movements, athletes who lack the necessary skills, strength, and ability present unstable movements. Our results showed that a significant relationship between motion screening tests, two leg squat and tuck jump tests, with athletes injuries. Based on the collected results, trainers and researchers are suggested to employ the Tuck jump, FMS, and double leg squat tests to predict injuries in wushu male players; this test can also be used to prevent injuries in players.

\section{Introduction}

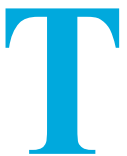

here exist various disciplines in the world of martial arts, each consisting of different characteristics and rules. These disciplines include Karate, Taekwondo, and Wushu, i.e., recognized as the most common martial arts [1]; they also enjoy a desirable position in Iran. The essential benefits of these sports can be the ability to self-defense, increase physical fitness factors as well as flexibility, and enhance the self-confidence of athletes [2]. However, accidents and injuries in martial arts, like other high-impact sports, are inevitable. Besides, athletes in these disciplines are always exposed to numerous potential risks [2].

With the rise in the number of participants in martial arts and according to the unique rules and techniques used in these sports, the number of injuries is expected to increase. According to studies, the number of lower limb injuries in martial arts has been reported as 59\% in Taekwondo and 30\% in Karate [1].

Wushu is among the most popular martial arts disciplines, originating in China. Most of the other martial arts are derived from this discipline. Wushu is a martial art that includes a combination of explosive, strength, and speed movements with combat techniques [3]. According to Pichet et al. (2014), the prevalence of wushu injuries at the 2009 Asian Championships was higher among women than men. Additionally, the highest prevalence of injury has been recorded in Mutai and Taekwondo [4]. The prevalence of injuries in this discipline, according to studies, is 22807 incidents per 1000 athletes. According to reports, there occurs 16176 injuries per 1000 male athletes and 32609 injuries per 1000 female athletes. The lower limb has the highest rate of injury (10294 injuries per 1000 athletes) [4].

Wushu competitions are held in the two styles of Sanda and Taolu. The Sanda section is performed as a fighting style, and the Taolu is conducted as a routine practice [5]. Sanda style is more susceptible to injury due to its fighting mode [6]. Performing hard and complicated movements, consistency in performing movements, and stability in performing techniques are the main factors in performing Taolu form in wushu competitions. The athlete holds the body in balance for a few seconds (about 3-5 seconds) while performing the technique at specific angles. A complexity of performing these movements is maintaining the body balanced by changing the movement of different parts of the body. The instability and vibration of the limbs cause points to be deducted from the athletes. In performing these movements, athletes who 
lack the necessary skills, strength, and ability present unstable movements [7]. However, for Sanda, keeping balance is essential, due to its fight style, to prevent injury in contacts, in hitting, and receiving the blow. Movements and blows are not foreseen in martial arts battles. Therefore, maintaining balance in unforeseen circumstances is more difficult and complicated $[8,9]$.

The ability to successfully predict injury is a crucial goal in pre-season tests. Determining the ability of individuals to participate in sports events requires a careful assessment of the needs of that sport and requires specialized screening [10]. Motion assessment allows health and fitness professionals to recognize muscle imbalances as well as the strategy and order of using muscles by observing motor defects [11]. Predicting lower limb injuries, if they can be measured with a simple, cost-effective, and valid test, is a major step to prevent lower limb complications [12]; subsequently, individuals with a high percentage of the injury risk can minimize this possibility by various strength and balance exercises.

Several tests have been proposed to predict injury. For example, Letafatkar et al. (2014) stated that FMS scores could predict harm in the active students [10]. O'connor et al. (2011) also prospectively evaluated the LESS test as a tool for the risk of knee ligament injury [13]. Based on their findings, the LESS score is an inappropriate tool for predicting knee ligament injuries. Plisky et al. (2006) stated that the star test is reliable for predicting lower limb injury [12].

Mirkarimpour et al. (2016) conducted a study using screening tests to predict injury in sports [14]. In their study, researchers examined FMS, SEBT, as well as the Y-balance test, LESS, and tuck jump. They concluded that factors, such as gender, history of injury, and participation in sports are essential and influential in the accuracy of these tests. They believed that their study results were inconsistent with those of the studies that introduced FMS as a predictor of injury. Researchers described the FMS test as incapable of predicting injury. However, SEBT and Y-balance tests could be predictors of injury. They also announced the LESS test as a tool for predicting injury after data analysis. Finally, the tuck jump test is useful in predicting injury. However, they argued that more studies are required in this regard [14]. In short, tests that are recognized as the predictors of injury generally include the Functional Movement Screening (FMS) tests. Tuck jumps, Single-leg Squat (SLS), Double-leg Squat (DLS), Stork Balance Test (SBT), Star Excursion Balance Test (SEBT), and Landing Error Scoring System (LESS).
The FMS is among the tests that numerous researchers agree on its ability to predict injuries in various sports [15]. However, contradictory study results are observed in the predictive power of this scale and some other performance inventories [16]. Given the nature of the wushu discipline, balance, and flexibility factors, along with other fitness characteristics, are of more importance. Implementing performance tests that challenge these factors will add to our knowledge concerning the effectiveness of these tests in predicting Wushu sports injuries. Thus, the present study aimed to investigate the relationship between these tests and sports injuries in the Wushu Sanda style.

\section{Materials and Methods}

This was a descriptive correlational study. The statistical population included male wushu players who participated in league competitions and national championship wushu competitions. Initially, 120 individuals were selected, and eventually, 100 wushu players were selected after reviewing the inclusion and exclusion criteria of the study. Wushu has two styles, Sanda and Taolu. Taolu style is dedicated to performing form and demonstrative movements; Sanda style is a confrontation and fighting one, which offers a complete set of martial arts. Given that Sanda (or Sanshu in Chinese) means free to struggle, the odds of injury to athletes is much higher in this style [3-5]. Therefore, Sanda style athletes were selected as the population and statistical sample in this study.

First, the information of all Sanda style Wushu athletes was prepared from the Wushu Federation for data collection. Next, 120 eligible athletes were considered to participate in the competitions. Then, the initial information form, including inclusion criteria, was completed by referring to the training place of athletes who lived in different cities. This step was conducted after receiving the consent form for participation in the research. Inclusion criteria included $\geq 3$ years of Sanda-style professional experience, no history of lower limb injury in the past 6 months, and no history of lower limb surgery in the past year. Exclusion criteria also included the athlete's dissatisfaction to record the injury during the research, the reluctance of the athlete to cooperate in performing all pre-competition performance tests, and early elimination during the competition. According to the study exclusion criteria, approximately 20 subjects were excluded from the study. In the present study, the injury was considered as any harm that occurred during league matches, leading to visiting a doctor and receiving required medical intervention by the athlete. Non-contact injuries were considered among the injuries, due to the nature of this study. 
Predicted performance tests were randomly performed for qualified athletes before training and competitions. Except for two tuck jump tests and the landing error scoring systems that required further camera and time, the research subjects were examined during training and competitions; in coordination with the team physician and the organizing committee, non-contact lower limbs injuries in athletes were also recorded using the injury registration form.

The functional tests of the present study included the tuck jump test, the One- and Two-Leg Squat, Stork Balance Test, FMS test, Star Balance test, and the LESS test. In the tuck jump test, the subject stands with his legs shoulder-width apart. This test is repeated for 10 seconds. When jumping, the subject raises two femurs to be parallel to the ground. Then, the subject lands on the previous position. The subject repeats this jump for 10 seconds. The subject is evaluated in the anterior and posterior directions using a camera. Ten defects in the subject's jumps are evaluated, including knee valgus when landing; thighs not reaching parallel to the ground; thighs failing to rise evenly; the position of the legs not being equal to the width of the shoulder; the legs not being parallel; the time of placing the feet on the ground is not equal; loud noise on landing; pause between jumps; jumping technique before 10 seconds, and the feet failing to land in their place [17]. Based on the previous studies, the reliability of this test has been reported to be 0.88 [18].

The one-leg squat test explores movement disorders of the motor chain, including pelvic obliquity, knee valgus, and the hyperpronation of the foot (subtalar joint). Accordingly, excellent, good, average, and low scores are assigned [19]. The reliability of this test is reported to be 0.87 [20]. The two-leg squat test has the features of a oneleg squat test. However, transferring body weight to the sides is also considered for evaluating the test, in addition to the parts mentioned in the one-leg squat test [21].

The stork balance stand test is used to assess the static balance. This test was designed as a standard tool for measuring static balance by Nelson and Johnson (1979). The test is performed in two cases with open and closed eyes, as follows: the subject stands on one leg with his hands on his waist. The sole of the other foot (free foot) rests on the inside of the knee. In this position, the subject stands on the supporting leg, and the examiner records his endurance time in this situation (seconds); the conditions that cause the whole test are as follows: the heel of the supporting leg is in contact with the ground, lifting the hands from the waist, and separating the free foot from the knee of the support leg [22]. The reliability of this test is reported to range between 0.61 and 0.81 [23].

The FMS test consists of 7 movements, as follows: full squat, launch (left \& right), rotational stability (left \& right), shoulder mobility (left \& right), trunk stability swimming, stepping over the obstacle (left \& right), as well as actively and directly raising the foot (right \& left). Each move is given three points starting from zero. If pain is experienced in the body during the movement, the athlete will be given a score of zero. If the subject is unable to move or is unstable during the movement, they are given a score of one. Score two is awarded if the person can perform the movement with a compensatory movement. A score of three is assigned to the individual when the movement is completed. Each test is repeated three times, and the total score equals 21 [24]. The reliability of this test is reported to range between 0.81 and 0.91 [25].

The Star Balance Stand Test is used to measure the dynamic balance. In this test, the athlete stands on one foot in the center of the circle with the heel in the center of the star and the toes on the line in the anterior direction. Then, the subject puts his hands on his hips and moves his other leg along the lines as much as he can; accordingly, the individual hits the ground with the maximum amount of approaching without bearing the weight to determine the extent of approaching. Then, the subject returns to the starting position (standing on both legs). The distance between the center of the star and the point of contact of the free foot is the extent of approaching. The foot length of the individual affects the distance he reaches. Therefore, the mean reaching distance is divided by the leg length of each test; subsequently, it is multiplied by 100 to calculate the dependent variable, and access distance is calculated as a percentage of foot length. This test is performed on both feet [26]. The reliability of this test is reported to range between 0.85 and 0.91 [27].

To evaluate the landing error test, initially, two cameras are installed in frontal and sagittal views at a distance of 4.8 and 4 meters, respectively. These two cameras record the jump performance from the mentioned views. This system is highly feasible and can clinically assess hazardous landing mechanics. To perform the test, the athletes jumped from a $31-\mathrm{cm}$ platform in the pretest session; next, they landed in front of the platform at a distance of about $21 \%$ of their height. Then, they immediately conducted a maximum vertical jump. During the test training, it was emphasized that the person should jump as high as possible as soon as he descended from the platform. No feedback or training was provided to the individual during the test unless he performed the test 
Table 1. The frequency of non-contact injuries in the studied subjects

\begin{tabular}{cc}
\hline Injury Type & No. (\%) \\
\hline Meniscus \& cartilage & $8(24.2)$ \\
\hline Sprain/ligament injuries & $11(33.3)$ \\
\hline Luxation & $2(6.1)$ \\
\hline Tendon injuries/rupture/tendonitis & $1(3)$ \\
\hline Ecchymosis/bruises & $5(15.2)$ \\
\hline Other injuries & $6(18.2)$ \\
\hline
\end{tabular}

Table 2. A summary of the results of the multivariate regression model

\begin{tabular}{cccccccccc}
\hline & $\mathbf{R}$ & $\mathbf{R}^{2}$ & Balanced & Std. Error Estimation & $\mathbf{F}$ & df1 & df2 & P \\
\hline Model & 0.413 & 0.171 & 0.098 & 0.413 & 2.342 & 8 & 91 & $* 0.025$ \\
\hline
\end{tabular}

* The level of significance: $\mathrm{P}<0.05$.

PHYSICAL TREATMENTS

incorrectly. After the test training, individuals were allowed to practice two jumps to learn it.

The athletes, then, performed three correct jumps. If the subject failed to reach the specified horizontal distance or make the maximum vertical jump after landing, that turn was removed, and the jump-landing maneuver was repeated once more. The landing error scoring test has 47 items. A set of these questions concerns the condition of the lower limbs and trunk at the moment of the first impact with the ground (items 1-6). Another set evaluates foot position errors (items 7-11) and assesses the errors at the moment of the first impact with the ground (item 11); the moment when the whole sole is in contact with the ground (items 6-8), and during the time of the first impact and the maximum angle of flexion of the knee (item $9 \& 10$ ).

The third set evaluates the movements of the lower limbs and trunk during the times of the first impact with the ground and the maximum angle of flexion of the knee (items 12-14), and the time of maximum and knee valgus (item 15). The final score for each landing is calculated by the sum of the scores of all items (0-15) [17]. Studies have reported the reliability of this test to range between 0.72 and 0.81 [28].

Descriptive tests, such as mean and standard deviation were used to describe the data, and a multivariate linear regression test with input method was applied along with selected functional tests to investigate the relationship between the incidence of injury and other variables.
All statistical operations were performed by SPSS at a significance level of $\mathrm{P}<0.05$.

Before conducting the research, a proposal was presented to the Ethics Committee of the Biomedical Research of the Institute of Sports Sciences for review with the permission of the Ministry of Health and Medical Education of Iran. After approving the proposal, the code IR.SSRC.REC.1398.031 was awarded to this research.

\section{Results}

The descriptive statistics data suggested that the mean age of the explored subjects was 25.47.9 years, their mean height was $175.4 \pm 4.6 \mathrm{~cm}$, and their mean weight was $67.87 .2 \mathrm{~kg}$. The frequency and percentage of noncontact injuries in Wushu players are presented in Table 1 , in which the highest rate of injury was related to ligament injuries (33.33\%). Meniscus and cartilage injuries were also in second place $(24.2 \%)$. Besides, the lowest rate of injury was related to tendon injuries and tears (3\%) (Tables 1-3).

According to Table 4, there was no significant relationship between the one-leg squat test, the landing error scoring system, star balance, stork balance, and the recorded injury during matches. However, there was a significant relationship between motor screening tests, two-leg squat, and tuck jump, and the explored athletes' injuries $(\mathrm{P}<0.005)$. 
Table 3. A summary of the results of the analysis of variance in multivariate regression test

\begin{tabular}{cccccc}
\hline Model & Sum of Squares & df & Mean Squares & F & P \\
\hline Regression & 3.201 & 8 & 0.400 & 2.342 & $* .025$ \\
Remainder & 15.549 & 91 & 0.171 & \\
\hline Total & 18.750 & 99 & $-\cdots$ & \\
\hline
\end{tabular}

* The level of significance: $\mathrm{P}<0.05$.

Table 4. Correlation coefficients and presentation of variables in multivariate regression test

\begin{tabular}{cccccc}
\hline Test & B & Standard Error & t & P & $0.005^{*}$ \\
\hline Tuck jump & -0.088 & 0.03 & -0.314 & -2.879 & 0.329 \\
\hline Stork balance (left foot) & -0.007 & 0.007 & -0.100 & -0.982 & 0.302 \\
\hline Stork balance (right foot) & -0.008 & 0.008 & -0.100 & -0.984 & 0.439 \\
\hline One-leg squat & 0.043 & 0.055 & 0.099 & 0.777 & $0.032 *$ \\
\hline Two-leg squat & -0.066 & 0.030 & -0.304 & -2.173 & 0.816 \\
\hline Star Balance & -0.002 & 0.006 & -0.032 & -0.281 & 0.006 \\
\hline The landing Error scoring System & 0.005 & 0.022 & 0.029 & 0.234 & $0.029 *$ \\
\hline FMS & 0.057 & 0.026 & 0.269 & 2,224 & \\
\hline
\end{tabular}

* The level of significance: $\mathrm{P}<0.05$.

\section{Discussion}

The study investigated the relationship between selected performance tests and non-contact sports lower limb injuries in Sanda male Wushu players. The findings indicated a significant relationship between motion screening tests, two leg squat and tuck jump tests, and athletes' injuries. Studies have revealed that the tuck jump test is useful for examining landing defects during plyometric exercises [29]. In the last decade, numerous researchers have evaluated the relationship between hip and knee mechanics during landing and cutting movements, using two- and three-Dimensional (3D) motion analysis systems. However, these methods cannot be used frequently due to complex analysis and high cost [30].

Lisman et al. (2008) evaluated the results of the tuck jump test and the reduced risk of injury [31]. The researchers stated that the tuck jump test could be used to diagnose neuromuscular imbalances that ultimately lead to knee injuries [31]. Tuck jumps are also employed to assess improvements in lower limb biomechanics. If the athletes can improve their neuromuscular control in the frequent tuck jumps, they are subsequently gaining control over the neuromuscular function of the knee joint; thus, they can improve the acquired skills and reduce the odds of injury. Performing a weaker leg tuck jump requires more effort to present balance performance between the two legs. However, neuromuscular adaptation occurs more frequently in weaker legs [29].

Chorba et al. (2016) evaluated the reliability of the screening assessments of the risk of tuck jump injury in young elite male soccer players [32]. They stated that the overall tuck jump score is reliable for assessing elite young soccer players; however, due to the within-subject variation, caution should be observed in the individual interpretation of the score combination [18]. Despite the better balance of women, compared to men, female athletes are more prone to be injured than men. This is because the women's landing pattern is associated with more valgus [32]. Therefore, by evaluating the tuck jump, successive tuck jumps with high valgus can indicate the susceptibility of injury to the lower limb. The reason for the inconsistency of the results of the present study with the study of Reed et al. (2016) could be the gender of the subjects, and the type of injury studied. This is because, in their study, the knee valgus was directly related to the type of ligament injury. However, the present study evaluated males, and a more comprehensive range of injuries was investigated. Garrison et al. (2011) stated that the tuck jump test could be a suitable 
predictor of injury to individuals and athletes during the match season [33]. The reason for the consistency of the results of the present study with those obtained by Garrison et al. (2011) can also be the study duration [33].

The FMS test is known as one of the most valid functional inventories for predicting the incidence of injury in athletes in various sports. Furthermore, the prediction ability of this test set has been repeatedly supported by previous studies. The present research findings demonstrated that the adequacy of each performance test could be affected by the type of sport and different athletes. This is because the nature of each sport requires different capabilities for athletes in that sport. Additionally, the individuals with a total score of $<14$ in the FMS test are 5.6 times more likely to be injured than those with higher and better overall scores [10].

Kiesel et al. (2007) examined the relationship between the FMS of English Premier League soccer players and the odds of severe injury [34]. They concluded that the FMS test could predict severe injuries in soccer. They argued that athletes with a lower rate of FMS are more prone to injury; and a score of $<14$ was considered as a positive predictor of severe injuries with $91 \%$ specificity and 54\% sensitivity, as well as 11.7 times higher probability of injury [34].

In this regard, Lisman et al. (2012) investigated the FMS test and the prediction of aerobic exercise injury. In this study, 447 subjects were examined. They concluded that running time is shorter with lower scores. This test can also predict injury in these athletes [31]. Chorba et al. (2010) used the FMS test to determine the risk of injury in female athletes [32]. They concluded that a score $<14$ on the test increased the probability of injury by 4 times [31-39]. The primary purpose of the FMS test is to assess the body's motor chain system [32]. The incidence of most upper limb injuries in martial arts is further, i.e., due to collisions, because the upper limbs fail to carry much weight. However, in the lower limbs, a change in the motor chain can easily cause injury due to the weight-bearing.

Most relevant studies have supported that the FMS test involves most of the lower limbs in soccer players or runners; thus, it is tangible that an FMS test can better predict injury in these disciplines, compared to the others [39-41]. Chimera et al. (2016) conducted a study using screening tests to predict injury in sports [42]. They examined the FMS test, star balance test, Y-balance test, the LESS, and tuck jump test. They accordingly documented the FMS test failed to predict injury. Nevertheless, the star balance test, the Y-balance test, and the LESS test could predict injury and introduced the tuck jump test as a useful scale in predicting effective injury. Finally, they stated that characteristics, such as gender, history of injury, and participation in sports are critical and influence the accuracy of these tests. Further studies are required in this area [14].

Hoover et al. (2008), as well as Sorensen et al. (2009), believed that the FMS could not predict the odds of injury due to a sensitivity of $<50 \%[28,29]$. They have a sensitivity of $8.3 \%$ and a specificity of $94.5 \%$ for marathon runners. Moreover, Sorensen suggested a sensitivity of $53.8 \%$ and $52.3 \%$ specificity for it.

One study that was very cautious about the ability of FMS to predict injury was conducted by O'connor et al. (2011) [13]. In their study, they examined 874 subjects. The results of their study revealed that FMS had 45\% sensitivity and $71 \%$ specificity for non-fatal and severe injuries; and $12 \%$ sensitivity and $94 \%$ specificity for severe injuries. Therefore, according to these results, the FMS lacks a high ability to predict injury [13].

Butler et al. (2013) also examined dynamic balance performance and lower limb injuries in 59 college soccer players [35]. They found that players who scored $<89.6 \%$ on the Y-balance test were 3.5 times more likely to be injured than the other players. They stated that the dynamic balance test during the pre-season phase was merely successful in identifying players prone to injury during the season [35].

In this study, the Y-balance test was applied to assess balance. The collected results indicated that low scores of the Y-balance test failed to predict injury-prone runners; it was also impossible for marathon runners to determine the risk of injury through the cut-off point of the Y-balance test. Scholars stated that the insignificance of the findings might be due to the broad age range of the subjects (age: 25-60 years), subjects' experience, the recording of minor injuries, and errors in surveys [43].

In contrast, Williams (2015), in a study on male and female marathon runners, observed no predictive association between injury incidence and dynamic balance performance [44]. Low scores on balance tests indicate the presence of neuromuscular control deficits as an essential risk factor for the occurrence of injuries [44].

Flippa (2010) believed that muscle coordination and proprioception significantly impact the performance of the star balance test and poor neuromuscular coordina- 
tion. It can negatively affect the dynamic stability of the lower limbs [45].

Khayambashi et al. (2017) conducted a study titled «predicting ankle and knee injuries by static balance test.» [46]. They found a significant relationship between athletes> balance and lower limb injuries. The related results indicated that the one-leg balance test could be used as a predictive scale in lower limb injuries [46]. McGuine et al. (2000) reported that postural oscillation can be a predictor of ankle injuries [47]. However, some studies did not consider having better balance as a determining factor in reducing the rate of injury in athletes. These studies include the one conducted by DiStefano et al. (2009). They concluded that although balance exercises reduce ligament damage, it, surprisingly, increases the risk of knee injury in women, and overuse in men [48].

Complicated steps must be performed to evaluate imaging, especially 3D imaging. The researchers employed video recording while moving to solve the limitations of such measurements; most of them have used the frontal surface view in two dimensions. One-leg and two-leg squat tests are very common, useful, and valid clinical screening tools to assess the condition of the trunk (central stability) and the entire lower limb [49].

Additionally, healthy female athletes, compared to male athletes, presented dorsiflexion and ankle pronation; internal rotation and hip adduction; external tibial rotation; reduced lateral flexion of the torso; anterior pelvic rotation; less hip flexion, and larger lower limb valgus in these tests [50]. Besides, there was a significant relationship between individuals performance in this test and the control of knee movement in the frontal plane and strength of thigh muscles [51]. It has also been suggested that the evaluation of angle and torque of the knee valgus predicts non-contact the Anterior Cruciate Ligament (ACL) injury with 78\% sensitivity and 73\% accuracy [52]. Various 2D lower limb assessment methods have been reported. All measurements employed motion assessment on the frontal plane using standard video cameras and standard software for motion analysis.

In ligament dysfunction, the muscles fail to fully absorb the ground reaction force, and joints and ligaments must absorb a large amount of force, shortly. The absorption of excessive force in a brief time can lead to ligament injuries. The reaction force of the ground controls the movements of the lower limbs and puts the knee in the valgus position [52, 53]. Although in several studies, the landing error scoring system tests were not introduced as predictors of injury, the validity of this test equals
0.84 [53]. In an extensive review study by Dallinga et al. (2012), they concluded that the landing error test is valid for predicting lower limb injury [54] According to studies, a five-degree increase in knee valgus enhances the pressure on the knee by up to 6 times [55]. The researchers also found that athletes with ACL injury encountered more abduction angles and torque, compared to healthy athletes during landing [55]. instead of using the leading lower limb movers, the individual uses anatomical structures and static stabilizers to absorb the ground reaction force [56].

The results of these studies are inconsistent with those of the present study. In the current study, the landing error test could not explain the relationship between lower limb injuries. The reasons for the inconsistency of these results are the type of discipline studied, gender, time, and the type of evaluation of variables.

\section{Conclusion}

Based on the collected results, among the studied tests, trainers and researchers are suggested to employ the Tuck jump, FMS, and double leg squat tests to predict injuries in wushu male players; this test can also be used to prevent injuries in players.

\section{Ethical Considerations}

\section{Compliance with ethical guidelines}

All ethical principles were considered in this article. The participants were informed about the purpose of the research and its implementation stages; they were also assured about the confidentiality of their information; moreover, they were allowed to leave the study whenever they wish, and if desired, the results of the research would be available to them. After describing the test protocol to all subjects before participating in the study, they all signed an informed consent form.

\section{Funding}

This paper extracted from the first author's master thesis in department of physical education and sport sciences, Karaj Branch, Islamic Azad University, Karaj, Iran.

\section{Authors' contributions}

Conceptualization, Methodology: Abbas Ghafouri, Fariba Mohammadi, and Behnaz Ganji; Supervision, Data collection, Writing - original draft, and Data analysis: Abbas Ghafouri, Fariba Mohammadi; Investigation: Fariba Mohammadi. 


\section{Conflict of interest}

The authors declared no conflict of interest.

\section{Acknowledgments}

We thank I.R Iran Wushu Federation, coaches, athletes, and physicians, and the Faculty of Physical Education of the Islamic Azad University, Karaj Branch, for assisting the researchers in this study and for their cooperation.

\section{References}

[1] Zetaruk MN, Violan MA, Zurakowski D, Micheli LJ. Injuries in martial arts: A comparison of five styles. British Journal of Sport Medicine. 2005; 39(1):29-33. [DOI:10.1136/ bjsm.2003.010322] [PMID] [PMCID]

[2] Moghadasi A, Ahanjan S, Taheri H, Abbasi Darebidi M. [A comparison of injury prevalence in non professional boys participating: Taekwondo, Karate and Judo (Persian)]. Journal of Applied Exercise Physiology. 2007; 3(6):11-29. http:// asp.journals.umz.ac.ir/article_1355.html?lang=en

[3] Emami F, Bahremand M, Rojhani-Shirazi Z. Prevalence of musculoskeletal injuries in shiraz male wushu players: A cross sectional study. Journal of Rehabilitation Sciences \& Research. 2017; 4(1):6-9. https://jrsr.sums.ac.ir/article_41111_a635483cb516f997cf7d8e10fbfe302c.pdf

[4] Yiemsiri P, Wanawan A. Prevalence of injuries in Wushu competition during the $1^{\text {st }}$ Asian Martial Arts Games 2009. Journal of the Medical Association of Thailand. 2014; 97(Suppl 2):S9-13. [PMID]

[5] Rui-hong HE. Correlated analysis of evaluated contents upon the new rules of wushu taolu in 2002. Journal of Beijing University of Physical Education. 2004; 10:46. https:/ en.cnki.com.cn/Article_en/CJFDTotal-BJTD200410046.htm

[6] Xuezhi M. Investigation and analysis of athletes' injuries in chinese national wushu sanda championship in 1999. Journal of Beijing University of Physical Education. 1999; 4:35. https://en.cnki.com.cn/Article_en/CJFDTOTALBJTD199904035.htm

[7] Yavari A, Tanbakoosaz A, Rostami M, Khanian MYA, Esteki A. Stability and control of human body motion during performing balance motion in Wushu. $19^{\text {th }}$ Iranian Conference of IEEE, 2012 December 20-21, Tehran, Iran; 2012 [DOI:10.1109/ICBME.2012.6519696]

[8] Babagoltabar Samakoush H, Norasteh A. Prevalence of postural abnormalities of spine and shoulder girdle in sanda professionals. Annals Applied Sport Science. 2017; 5(4):31-8. [DOI:10.29252/aassjournal.5.4.31]

[9] Zhang H, He Z. Comparsion of dynamic balance ability between wushu routine and sanda of college students. Journal of Yanan University (Natural Science Edition). 2015; 3:25.

[10] Letafatkar A, Hadadnezhad M, Shojaedin S, Mohamadi E. Relationship between functional movement screening score and history of injury. International Journal of Sports Physical Therapy. 2014; 9(1):21-7. [PMCID]

[11] McGill SM, Andersen JT, Horne AD. Predicting performance and injury resilience from movement quality and fitness scores in a basketball team over 2 years. Journal of Strength and Conditioning Research. 2012; 26(7):1731-9. [DOI:10.1519/JSC.0b013e3182576a76] [PMID]

[12] Plisky PJ, Rauh MJ, Kaminski TW, Underwood FB. Star excursion balance test as a predictor of lower extremity injury in high school basketball players. The Journal of Orthopaedic and Sports Physical Therapy. 2006; 36(12):911-9. [DOI:10.2519/jospt.2006.2244] [PMID]

[13] O'connor FG, Deuster PA, Davis J, Pappas CG, Knapik JJ. Functional movement screening: predicting injuries in officer candidates. Medicine and Science in Sports and Exercise. 2011; 43(12):2224-30. [DOI:10.1249/MSS.0b013e318223522d] [PMID] 
[14] Mirkarimpour SH, Falah Mohamaddi M, Alizadeh MH. Effect of functional fatigue on landing mechanics using Landing Error Scoring System (LESS). Scientific Journals Management System. 2015; 13(9):24-36. [DOI:10.18869/acadpub.jsmt.13.9.24]

[15] Hoog P, Warren M, Smith CA, Chimera NJ. Functional hop tests and tuck jump assessment scores between female division I collegiate athletes participating in high versus low ACL injury prone sports: A cross sectional analysis. International Journal of Sports Physical Therapy. 2016; 11(6):945-53. [PMCID]

[16] Bailey R, Selfe J, Richards J. The single leg squat test in the assessment of musculoskeletal function: A review. Physiotherapy Practice and Research. 2011; 32(2):18-23. [DOI:10.3233/PPR-2011-32204]

[17] Trulsson A, Miller M, Hansson G-A, Gummesson C, Garwicz $\mathrm{M}$. Altered movement patterns and muscular activity during single and double leg squats in individuals with anterior cruciate ligament injury. BMC Musculoskeletal Disorders. 2015 16:28. [DOI:10.1186/s12891-015-0472-y] [PMID] [PMCID]

[18] Ghaeeni S, Samoolar S. [Static and dynamic balance of the healthy elderly men at different times of the day (Persian)]. Iranian Journal of Ageing. 2015; 10(3):36-43. http://salmandj.uswr.ac.ir/article-1-654-en.htm

[19] Cook G, Burton L, Hoogenboom B. Pre-participation screening: The use of fundamental movements as an assessment of function-part 1. North American Journal of Sports Physical Therapy : NAJSPT. 2006; 1(2):62-72. [PMCID]

[20] Harkins KM, Mattacola CG, Uhl TL, Malone TR, McCrory JL. Effects of 2 ankle fatigue models on the duration of postural stability dysfunction. Journal of Athletic Training. 2005; 40(3):191-4. [PMCID]

[21] Myer GD, Ford KR, Hewett TE. Rationale and clinical techniques for anterior cruciate ligament injury prevention among female athletes. Journal of Athletic Training. 2004 39(4):352-64. [PMCID]

[22] Earl JE, Monteiro SK, Snyder KR. Differences in lower extremity kinematics between a bilateral drop-vertical jump and a single-leg step-down. The Journal of Orthopaedic and Sports Physical Therapy. 2007; 37(5):245-52. [DOI:10.2519/ jospt.2007.2202] [PMID]

[23] Myer GD, Ford KR, Hewett TE. Tuck jump assessment for reducing anterior cruciate ligament injury risk. Athletic Therapy Today: The Journal for Sports Health Care Professionals. 2008; 13(5):39-44. [DOI:10.1123/att.13.5.39] [PMID] [PMCID]

[24] Read PJ, Oliver JL, de Ste Croix MBA, Myer GD, Lloyd RS Reliability of the Tuck Jump injury risk screening assessment in elite male youth soccer players. Journal of Strength and Conditioning Research. 2016; 30(6):1510-6. [DOI:10.1519/ JSC.0000000000001260] [PMID] [PMCID]

[25] Henry JC, Kaeding C. Neuromuscular differences between male and female athletes. Current Women's Health Reports. 2001; 1(3):241-4. [PMID]

[26] Klugman MF, Brent JL, Myer GD, Ford KR, Hewett TE. Does an in-season only neuromuscular training protocol reduce deficits quantified by the tuck jump assessment?. Clinics in Sports Medicine. 2011; 30(4):825-40. [DOI:10.1016/j. csm.2011.07.001] [PMID] [PMCID]
[27] Zarei M, Asady Samani Z, Reisi J. [Can functional movement screening predict injuries in Iranian soldiers? (Persian)]. Journal of Military. 2015; 17(2):107-14. http://militarymedj.ir/article-1-1356-en.html

[28] Hoover D, Killian CB, Bourcier B, Lewis S, Thomas J, Willis $R$. Predictive validity of the functional movement screentm in a population of recreational runners training for a half marathon. Medicine \& Science in Sports \& Exercise. 2008; 40(5):S219. [DOI:10.1249/01.mss.0000322401.36429.15]

[29] Sorenson EA. Functional movement screen as a predictor of injury in high school basketball athletes [PhD. Dissertation]. United States: University of Oregon; 2009. https:/ / scholarsbank.uoregon.edu/xmlui/handle/1794/10594

[30] Schneiders AG, Davidsson A, Hörman E, Sullivan SJ. Functional movement screen normative values in a young, active population. International Journal of Sports Physical Therapy. 2011; 6(2):75-82. [PMCID]

[31] Lisman P, O'Connor FG, Deuster PA, Knapik JJ. Functional movement screen and aerobic fitness predict injuries in military training. Medicine and Science in Sports and Exercise. 2013, 45(4):636-43. [DOI:10.1249/MSS.0b013e31827a1c4c] [PMID]

[32] Chorba RS, Chorba DJ, Bouillon LE, Overmyer CA, Landis JA. Use of a functional movement screening tool to determine injury risk in female collegiate athletes. North American Journal of Sports Physical Therapy: NAJSPT. 2010; 5(2):47-54. [PMCID]

[33] Garrison M, Westrick R, Johnson MR, Benenson J. Association between the functional movement screen and injury development in college athletes. International Journal of Sports Physical Therapy. 2015; 10(1):21-8. [PMCID]

[34] Kiesel K, Plisky PJ, Voight ML. Can serious injury in professional football be predicted by a preseason functional movement screen. North American Journal of Sports Physical Therapy: NAJSPT. 2007; 2(3):147-58. [PMCID]

[35] Butler RJ, Lehr ME, Fink ML, Kiesel KB, Plisky PJ. Dynamic balance performance and noncontact lower extremity injury in college football players: An initial study. Sports Health. 2013; 5(5):417-22. [DOI:10.1177/1941738113498703] [PMID] [PMCID]

[36] Mackenzie W. Y-balance test as a predictor of injury occurrence in mit runner [MSc. Thesis]. United States: Otterbein University; 2015

[37] Gribble PA, Hertel J, Plisky P. Using the Star Excursion Balance Test to assess dynamic postural-control deficits and outcomes in lower extremity injury: A literature and systematic review. Journal of Athletic Training. 2012; 47(3):339-57. [DOI:10.4085/1062-6050-47.3.08] [PMID] [PMCID]

[38] Crossley KM, Zhang W-J, Schache AG, Bryant A, Cowan SM Performance on the single-leg squat task indicates hip abductor muscle function. The American Journal of Sports Medicine. 2011;39(4):866-73. [DOI:10.1177/0363546510395456] [PMID]

[39] Hewett TE, Myer GD, Ford KR, Heidt Jr RS, Colosimo AJ, McLean SG, et al. Biomechanical measures of neuromuscular control and valgus loading of the knee predict anterior cruciate ligament injury risk in female athletes: A prospective study. The American Journal of Sports Medicine. 2005; 33(4):492-501. [DOI:10.1177/0363546504269591] [PMID] 
[40] Padua DA, Boling MC, DiStefano LJ, Onate JA, Beutler AI, Marshall SW. Reliability of the landing error scoring systemreal time, a clinical assessment tool of jump-landing biomechanics. Journal of Sport Rehabilitation. 2011; 20(2):145-56. [DOI:10.1123/jsr.20.2.145] [PMID]

[41] Hrysomallis C. Relationship between balance ability, training and sports injury risk. Sports Medicine (Auckland, N.Z.). 2007; 37(6):547-56. [DOI:10.2165/00007256-200737060-00007] [PMID]

[42] Chimera NJ, Warren M. Use of clinical movement screening tests to predict injury in sport. World Journal of Orthopedics. 2016; 7(4):202-17. [DOI:10.5312/wjo.v7.i4.202] [PMID] [PMCID]

[43] Stensrud S, Myklebust G, Kristianslund E, Bahr R, Krosshaug T. Correlation between two-dimensional video analysis and subjective assessment in evaluating knee control among elite female team handball players. British Journal of Sports Medicine. 2011; 45(7):589-95. [DOI:10.1136/ bjsm.2010.078287] [PMID]

[44] Willson JD, Ireland ML, Davis I. Core strength and lower extremity alignment during single leg squats. Medicine and Science in Sports and Exercise. 2006; 38(5):945-52. [DOI:10.1249/01.mss.0000218140.05074.fa] [PMID]

[45] Filipa A, Byrnes R, Paterno MV, Myer GD, Hewett TE. Neuromuscular training improves performance on the star excursion balance test in young female athletes. The Journal of Orthopaedic and Sports Physical Therapy. 2010; 40(9):551-8. [DOI:10.2519/jospt.2010.3325] [PMID] [PMCID]

[46] Khayambashi K, Ghoddosi N, Falah A. [Prediction of ankle and knee injuries with static leg balance test (Persian)]. Journal of Sport Medicine Review. 2017; 8(20):17-36. https:// www.magiran.com/paper/1668154?lang=en

[47] Mcguine TA, Greene JJ, Best T, Leverson G. Balance as a predictor of ankle injuries in high school basketball players. Clinical Journal of Sport Medicine: Official Journal of the Canadian Academy of Sport Medicine. 2000; 10(4):239-44. [DOI:10.1097/00042752-200010000-00003] [PMID]

[48] DiStefano LJ, Padua DA, DiStefano MJ, Marshall SW. Influence of age, sex, technique, and exercise program on movement patterns after an anterior cruciate ligament injury prevention program in youth soccer players. The American Journal of Sports Medicine. 2009; 37(3):495-505. [DOI:10.1177/0363546508327542] [PMID]

[49] Noyes FR, Barber-Westin SD, Fleckenstein C, Walsh C, West $\mathrm{J}$. The drop-jump screening test: difference in lower limb control by gender and effect of neuromuscular training in female athletes. The American Journal of Sports Medicine. 2005; 33(2):197-207. [DOI:10.1177/0363546504266484] [PMID]

[50] McLean SG, Lipfert SW, Van Den Bogert AJ. Effect of gender and defensive opponent on the biomechanics of sidestep cutting. Medicine and Science in Sports and Exercise. 2004; 36(6):1008-16. [DOI:10.1249/01.MSS.0000128180.51443.83] [PMID]

[51] Hewett TE, Ford KR, Hoogenboom BJ, Myer GD. Understanding and preventing acl injuries: Current biomechanical and epidemiologic considerations-update 2010. North American Journal of Sports Physical Therapy: NAJSPT. 2010; 5(4):234-51. [PMCID]

[52] Bendjaballah MZ, Shirazi-Adl A, Zukor DJ. Finite element analysis of human knee joint in varus-valgus. Clinical Biomechanics (Bristol, Avon). 1997; 12(3):139-48. [DOI:10.1016/ S0268-0033(97)00072-7]
[53] Malinzak RA, Colby SM, Kirkendall DT, Yu B, Garrett WE. A comparison of knee joint motion patterns between men and women in selected athletic tasks. Clinical Biomechanics (Bristol, Avon). 2001; 16(5):438-45. [DOI:10.1016/S02680033(01)00019-5]

[54] Dallinga JM, Benjaminse A, Lemmink KAPM. Which screening tools can predict injury to the lower extremities in team sports? Sports Medicine (Auckland, N.Z.). 2012; 42(9):791-815. [DOI:10.1007/BF03262295] [PMID]

[55] Smith HC, Johnson RJ, Shultz SJ, Tourville T, Holterman LA, Slauterbeck J, et al. A prospective evaluation of the Landing Error Scoring System (LESS) as a screening tool for anterior cruciate ligament injury risk. The American Journal of Sports Medicine. 2012; 40(3):521-6. [DOI:10.1177/0363546511429776] [PMID] [PMCID]

[56] Padua DA, DiStefano LJ, Beutler AI, De La Motte SJ, DiStefano MJ, Marshall SW. The landing error scoring system as a screening tool for an anterior cruciate ligament injuryprevention program in elite-youth soccer athletes. Journal of Athletic Training. 2015; 50(6):589-95. [DOI:10.4085/10626050-50.1.10] [PMID] [PMCID] 